\title{
Terrestrial carbon dynamics through time - insights from downcore radiocarbon dating
}

RIENK SMITTENBERG ${ }^{1,2}$, VALIER GALY $^{3}$, MERLE GIERGA $^{2,4}$, AXEL BIRKHOLZ ${ }^{2,5}$, MUHAMMED USMAN ${ }^{2,6}$, CAMILO PONTON $^{3,7}$, IRKA HAJDAS ${ }^{2}$, LUKAS WACKER ${ }^{2}$, NEGAR HAGHIPOUR ${ }^{2}$, LIVIU GIOSAN ${ }^{3}$, STEFANO M. BERNASCONI $^{8}$ AND TIMOTHY IAN EGLINTON ${ }^{2}$

${ }^{1}$ Stockholm University

${ }^{2}$ ETH Zurich

${ }^{3}$ Woods Hole Oceanographic Institution

${ }^{4}$ University of Cologne

${ }^{5}$ University of Basel

${ }^{6}$ University of Toronto

${ }^{7}$ Western Washington University

${ }^{8}$ ETH Zürich

Presenting Author: rienk.smittenberg@geo.su.se

A relatively small change in the balance of in- and outgoing fluxes between terrestrial Carbon $\left(\mathrm{C}_{\text {terr }}\right)$ and the atmosphere, sustained over centuries to millennia can change $C_{\text {terr }}$ from a carbon source to a sink. The net carbon balance of any ecosystem is mainly determined by climate (temperature, humidity, seasonality), via its influence on primary productivity, respiration and preservation, and by geomorphology (erosion). More recently, human perturbance has increasingly also become a major factor. In particular, the slow cycling component of $\mathrm{C}_{\text {terr }}$, with turnover times of centuries to millennia, is relevant for the long-term carbon balance on land. Build-up of this carbon pool is inherently slow, but loss can be rapid and thereby form a significant carbon source to the atmosphere. One way to gain insight in the dynamics of this slow cycling carbon pool is to interrogate sedimentary records that, through time, have stored snapshots of terrestrial carbon, the latter being a mixture of preaged, long-stored $\mathrm{C}_{\text {terr }}$ and fresh material. By downcore measurements of the radiocarbon age of specific plant-derived organic compounds, interferences by aquatically produced organic carbon or petrogenic organic carbon can be circumvented, and insights can be gained into the carbon cycle processes in the corresponding catchment area. This study presents compound-specific ${ }^{14} \mathrm{C}$ data compiled from studies over the last 20 years of sedimentary records derived from small lake catchments to deltaic and submarine fan deposits near large river mouths. The main conclusions that can be drawn are: 1) Modern but also (pre)historic human perturbance through land-use change has released long-stored ecosystem carbon that otherwise would have escaped mobilization. 2) Both positive and negative correlations between millennial-scale hydroclimate change and $\mathrm{C}_{\text {terr }}$ dynamics are evident, and are attributed to the opposing effects on primary productivity, respiration and erosion rates. 3 ). Catchment size and geomorphology also influence the extent of net ecosystem carbon storage. 4). The Younger Dryas cold period promoted release of $\mathrm{C}_{\text {terr }}$ built up during the preceding warm Bølling-Allerød period, illustrating the role rapid climate change can play in carbon dynamics. 